\title{
Nanopore Sequencing SARS-CoV-2 genome in Qatar
}

\author{
Fatiha M. Benslimane, Hebah A. Al-Khatib, Dana Albatesh, Ola Al-Jamal, Sonia Boghattas, \\ Asmaa A. Althani, Hadi M. Yassine \\ Biomedical Research Center, Qatar University, PO Box 2713, Doha, QATAR
}

\section{BACKGROUND}

The current pandemic, Coronaviruses Disease (COVID-19), is cause by an RNA coronavirus that was recently identified as Severe Acute Respiratory Syndrome Coronavirus 2 (SARS-CoV-2). RNA viruses tend to have a high mutation rate; the rate is around a million times greater than that of their hosts. The mutagenic potential of the virus depends on many factors, including the fidelity of nucleic acid-replicating viral enzymes, such as SARS-CoV-2 RNA dependent RNA polymerase (RdRp). The rate of mutation drives viral evolution and genome variability, consequently allowing viruses to escape the immunity of the host and develop resistance to drugs. Therefore, the characterization of SARS-CoV-2 variants might lead to implement better therapeutics treatments, vaccines design and identify new diagnostics approaches.

\section{AIM}

The aim of this study is to establish a fast sequencing method to identify SARS-CoV-2 mutations. This will help to assess if there are new viral variants that are spreading in Qatar.

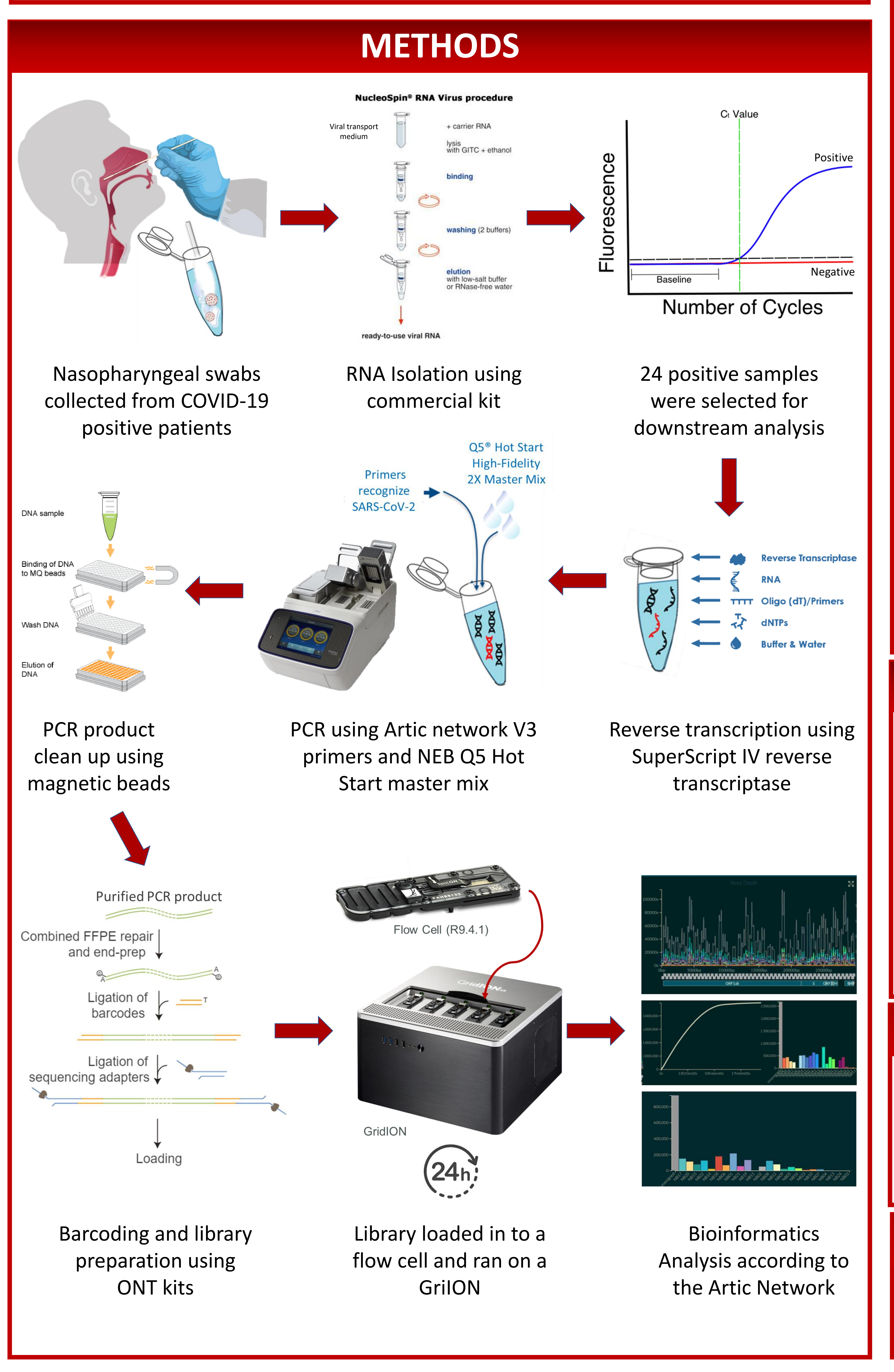

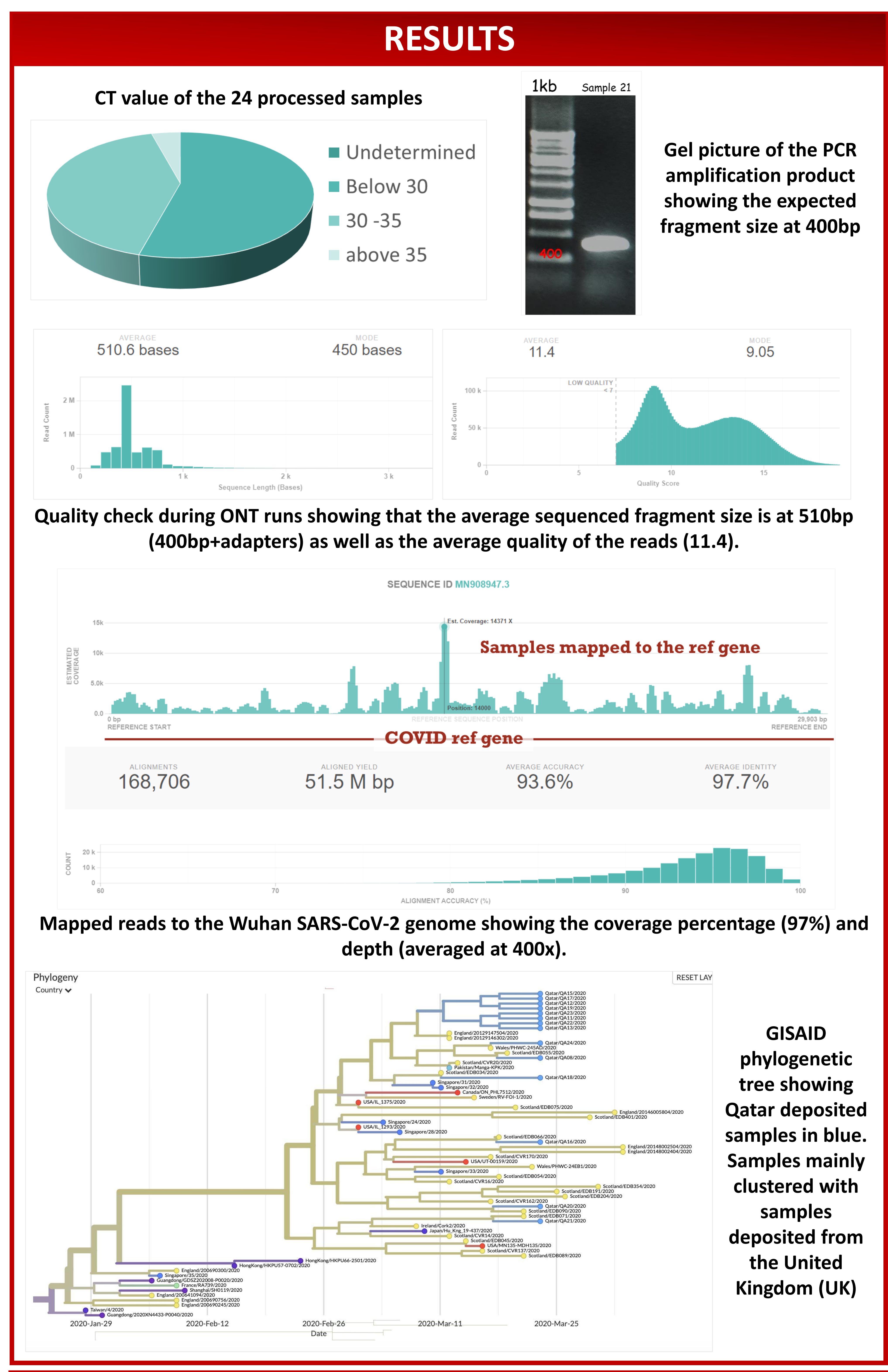

\section{CONCLUSION}

The use of ONT in combination with V3 primers that are recommended by the Artic Network to sequences SARA-CoV-2 generates genomes at $>80 \%$ coverage, $200 x$ depth in less than 24 hours. As such it is a quick, affordable, and reliable technique to determine viral mutations. Using this technique, the first sequences from Qatar were deposited in to GISAID. This technique has now been used to sequence over 700 genomes in Qatar.

\section{ACKNOWLEDGEMENT}

This work was supported by Qatar Petroleum under Qatar University external grant number (QUEX-BRC-GH-18/19) and Qatar Genome Project. We acknowledge the support from the Ministry of Public Health, Doha, Qatar, the virology laboratory in Hamad Medical Corporation, Doha, Qatar, and Qatar BioBank, Doha, Qatar, for their efforts in the preparation of nasopharyngeal samples and collection of clinical data.

\section{REFERENCES}

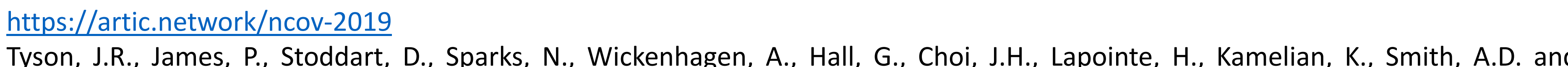
Prystajecky, N., 2020. Improvements to the ARTIC multiplex PCR method for SARS-CoV-2 genome sequencing using nanopore. bioRxiv. 